\title{
Postnatal care utilization and associated factors among women of reproductive age Group in Halaba Kulito Town, Southern Ethiopia
}

Teshome Abuka Abebo* and Dawit Jember Tesfaye

\begin{abstract}
Background: Despite postnatal care services significant role in improving maternal and new-born health, services are underutilized in most developing countries including Ethiopia. Hence, it is important to identify factors that facilitate or impede postnatal care services utilization. The aim of this study was to assess postnatal care services utilization and associated factors among reproductive age women who gave live birth in 2015 at Halaba kulito town, Southern Ethiopia.
\end{abstract}

Methods: A community-based cross-sectional study was conducted on 401 reproductive age women who gave live birth a year prior to the survey. Data were collected by using structured questionnaire. Bivariate and multivariable logistic regression analysis were carried out to identify factors associated with postnatal care services utilization. A significant association was declared when $p$-value is less than 0.05 . The strength of association was determined by calculating odds ratio at 95\% confidence interval.

Result: In this study, postnatal care services utilization by reproductive age women was $47.9 \%$. Multivariable analysis revealed that government employed $(A O R=3.01,95 \% \mathrm{Cl}=1.36,6.67)$, have three $A N C$ visits $(A O R=4.29,95 \% \mathrm{Cl}=1.59$, 11.55), have four $A N C$ visits $(A O R=9.55,95 \% C l=(3.46,26.39)$, gave last birth at Health Centre $(A O R=10.76,95 \% C l=3$. 26, 35.57), gave last birth at Hospital $(\mathrm{AOR}=13.15,95 \% \mathrm{Cl}=(3.64,47.50)$, didn't aware of at least one postpartum danger signs ( $A O R=0.06,95 \% \mathrm{Cl}=(0.01,0.37)$, didn't know child care and had three $\mathrm{ANC}$ visits $(\mathrm{AOR}=0.14,95 \% \mathrm{Cl}(0$. $02,0.8$ ), and didn't know child care and had four or more ANC visits ( $A O R=0.13,95 \% \mathrm{Cl}(0.02,0.79)$ were significantly associated with postnatal care services utilization.

Conclusion: This study assessed PNC services utilization and associated factors among reproductive age women. The study results provided a basic understanding of factors that associated with PNC services utilization by reproductive age women. The findings of this study showed direct association between postnatal care utilization and maternal employment, awareness to postpartum danger signs, frequency of ANC and attending birth at health institution. Therefore, the results suggested context-specific evidence which might be taken into consideration when rethinking policies to increase PNC utilization.

Keywords: Postnatal care, Reproductive age, Women

\footnotetext{
* Correspondence: teshabuka@gmail.com

School of Public and Environmental Health, Hawassa University College of

Medicine and Health Sciences, Hawassa, Ethiopia
} 


\section{Background}

Postnatal period is the time period from birth to 42 days after birth. It is a period where most of the maternal and new-born death occur. Immediately after birth, bleeding and infection pose the greatest risk to the mother's life, while preterm birth, asphyxia, and severe infections pose the greatest risk to newborn [1, 2]. Most maternal and newborn deaths are avoidable because healthcare solutions to prevent or manage complications related to pregnancy and birth are well known. All these maternal and neonatal problems could be reduced if women receive appropriate postnatal care [1].

Postnatal care (PNC) is one of the recommended strategies to reduce the maternal and new-born deaths during the postpartum period $[3,4]$. Hence, World Health Organization (WHO) recommends mothers and newborns should receive PNC in health facilities for at least $24 \mathrm{~h}$ after birth, if birth is in a health facility. While, if birth is at home, the first postnatal contact should be as early as possible within $24 \mathrm{~h}$ of birth. At least three additional postnatal contacts are recommended for all mothers and newborns on day 3 (48-72), between days 7-14 after birth, and six weeks after birth [4]. However, In Africa, most of mothers and newborns did not visit the health institution following birth, indicating that postnatal care programs are among the weakest of all reproductive and child health programs [5].

In Ethiopia, the level of postnatal care coverage is extremely low. A 2011 Ethiopian Demographic and Health survey (EDHS) revealed that great majority of women (92\%) with a live birth in the preceding five years did not receive a postnatal check-up. Also, it pointed out that there was regional variation in PNC utilization. Four instance in the Southern Nations, Nationality and Peoples Region (SNNPR), reported that the percentage of women had a postnatal checkup in the first two days after they gave birth was only 5.4\% whereas in Addis Ababa was 47.7\% [6]. Similarly, other studies conducted in different parts of Ethiopia revealed that PNC utilization by reproductive age women is low [7-13]. Meanwhile, in the Health Sector Transformation Plan (HSTP) 2015/16 Ethiopian government set a target of $95 \%$ postnatal coverage by the year 2020 [12].

Evidence showed that PNC services utilization is influenced by factors such as; maternal age, educational level of the women, occupational status of women and husbands, place of delivery, mode of delivery, the number of pregnancies, awareness about obstetric related danger sign, and awareness about PNC services [7-21].

However, factors influencing PNC services utilization vary from place to place in relation to culture and socioeconomic status of given society. Thus, assessing factors influencing postnatal care utilization in the study area is important to design public health intervention to improve PNC utilization. So that, this study was aimed to assess postnatal care utilization and associated factors among women who gave live birth in 2015 in Halaba Kulito town, Southern Ethiopia.

\section{Methods}

\section{Study design, setting, and population}

A community-based cross-sectional study was conducted from May 1 to 30, 2016 in Halaba kulito town. The town is administrative centre of Halaba special district which is found in Southern Nation Nationality and Peoples Region (SNNPR). It is located $245 \mathrm{~km}$ south from Addis Ababa through Worabe district and $90 \mathrm{~km}$ from Hawassa, the capital city of SNNPR. The town has five kebeles (smallest administrative units in Ethiopia). The estimated total population residing in the town is 39,507 people, with consisting of males 19,358 (49\%) and females 20,149 (51\%) of the population. Reproductive age group women account 9205 (23.2\%) of total female population. Population density of the town is 4 persons per hectare and the average family size is estimated to be 6 . In the town there are one health centre and one primary hospital. Basic essential obstetric care is provided in the health centre while comprehensive essential obstetric care is provided in the primary hospital. All reproductive age women who gave live birth in 2015 and resident of the town were included in the study population. Those women who had difficulty in communication due to severe illness were excluded from the study.

\section{Sample size determination and procedure}

The sample size for PNC utilization was computed by using single population proportion formula by assuming that proportion of PNC utilization was 0.2 [8], $95 \%$ confidence interval, $4 \%$ margin of error and considering $10 \%$ of non-response rate. The final sample size was 422. Whereas double population formula was used to compute sample size to identify factors associated with PNC use. The computation was made via StatCalc application of Epi. Info version 7 with impute of $95 \%$ confidence interval, $80 \%$ power and case to control ratio 1:1. Odds ratio and expected prevalence of exposure among non-users were taken from studies previously conducted in the country [6, $9,28]$. Some of the exposure variables used to compute sample size were new at least one post postpartum danger sign $(N=214)$, ANC use $(N=236)$, and place of delivery $(N=206)$. Maximum sample size obtained was (total $N=367$ ). However, sample size calculated using single population formula was judged sufficient source to identify associated factors with PNC services utilization. 
Five kebeles found in the town were included in the study. Then after, total sample size was proportionally allocated to each kebele and systematic random sampling was used to select households where eligible women were living. First household was selected by lottery methods and then the remaining households were selected by skipping K-intervals. The units of analysis for this study were women (aged 15-49 years) who gave live birth in 2015 .

\section{Definition of operational terms}

\section{Postnatal care services utilization}

Women and newborns have at least one check-up by the skilled health professional within 42 days after birth at the health facility.

\section{Postpartum danger sign awareness}

If mother mentions at least one postpartum complication of mother and newborn occur after birth such as vaginal bleeding, fever, edema, unable to suck, vomiting everything etc.... coded 1 (Yes) and if not coded 0 (No).

\section{Postnatal care awareness}

If the mother mention at least one service from postnatal care services (counselling on breastfeeding, child care, immunization, family planning etc....) coded 1 (Yes) and if not coded 0 (No).

\section{Antenatal care utilization}

Women have at least one check-up by the skilled health professional during her last pregnancy period.

\section{Knew child care}

If mother mentions at least one among child cares coded 1 (Yes) and if not coded 0 (No).

\section{Reproductive age women}

women whose age is between 15 and 49 years.

\section{Data collection and quality assurance}

Data were collected using structured, closed ended interviewer administered questionnaire. The questionnaire was prepared in English and translated to Amharic. The dependent variable was PNC service utilization; and independent variables included in the questionnaire were socio-demographic characteristics, obstetric history, awareness about postpartum danger signs, ANC utilization, place of delivery and awareness about PNC service. Before actual data collection started two days training was given for data collectors on the objective, sampling procedure, and process of data collection by the principal investigators. The questionnaire was pre-tested on $10 \%$ of the calculated sample size. Additional adjustments in the sequence and wording of the questionnaire were made based on the results of the pre-test. Five BSC in public health participated in data collection through home visit. The collected data were checked daily for completeness and consistency by principal investigators.

\section{Data processing and analysis}

Data entry, cleaning, and analysis were done using SPSS version 20.0 software. Binary logistic regression was used to identify independent effect of each independent variables on the outcome variables and multivariable logistic regression analysis used to control confounders and identify factor associated with PNC services utilization. The "Backward: conditional" method was used to perform the multivariable analyses. Interactions were explored and interaction was observed. Absence of multicollinearity among independent variables was checked. Variable whose variance inflation factor (VIF) greater than 10 were not entered to multivariable analysis [31] Appendix 1. The fitness of logistic regression models was assessed using the Hosmer-Lemeshow test. In bivariate and multivariable logistics regression analysis, a significant association was declared when the $p$-value was less than 0.05 and strength of association was determined by computing odds ratio at 95\% CI.

\section{Ethical consideration}

Support letter was obtained from Hawassa University College of Medicine and Health Sciences Ethical review board. Permission to proceed the study was attained from the town health office administrative officials. Verbal consent was obtained from the study participants after the brief explanation given on the objectives as well as the benefit of the study. Confidentiality and privacy of every respondent's information were ensured by not using any identifiers of the study participants.

\section{Result}

In this study, four hundred one women were interviewed from four hundred twenty two with a response rate of $95 \%$. More than half, 246 (61.3\%) of the participant were found between the age of 18 to 29 . Regarding religion, the majority of respondents were Muslim 221 (55.1\%) followed by Orthodox 120 (29.9\%). Majority 357 (89.0\%) of respondents were married. Concerning the educational level of mothers, $63(15.7 \%)$ of the respondents were illiterate, 129 (32.2\%) attended primary education and 150 (37.4\%) attended junior secondary to high school education. A husband who attended college and above were 126 (31.4\%) whereas who attended junior secondary to high school education were 167 (41.7\%). Regarding occupation 152 (37.9\%) of the mother were a housewife, 68 (17.0\%) were government employed and 145 (36.2\%) were self-employed. The majority of husband 201 (50.1\%) were a merchant. Households which had a monthly income of $<500$ Ethiopia Birr (ETB) 
were 51 (12.7\%) while 129 (32.2\%) households had a monthly income between 1501 and 2500 ETB and 99(24.7\%) households had a monthly income of 2501 ETB and above (Table 1).

\section{Obstetric characteristics, and postnatal care utilization}

One hundred sixty-five (41.1\%) respondents were pregnant for three and more times. One hundred forty-one $(35.5 \%)$ respondents had three and more alive children. The majority of respondents 362 (90.3\%) attended ANC during their last pregnancy. Among ANC attendants 111 (30.7\%) attended for four and more times. Respondents who gave their last birth at the health center and hospital were 277 (69.1\%) and 85 (21.2\%) (Table 2).

Overall PNC utilization among reproductive age women was $47.9 \%(95 \% \mathrm{CI}=(0.43,0.53)$. The first within $24 \mathrm{~h}$ after birth and the last 42 days after birth visits of PNC were more utilized. Husband and wife jointly made a decision in $91 \%$ cases to utilize PNC. Majority 371(92.5\%) of respondents aware of at least one danger signs of postpartum. Health professional were leading sources of information 268 (72.2\%). More than half (56.9\%) of mothers knew at least four PNC services (Table 2).

\section{Factors associated with PNC utilization}

At bivariate analysis socio-demographic factors associated with PNC utilization were maternal education, maternal occupation, paternal education, paternal occupation, and household monthly income (Table 1). Likewise, factors such as frequency of ANC, aware of at least one postpartum danger sign, and place of delivery were associated with PNC utilization (Table 2).

Interactions were checked for variables found at the final model in multivariable analysis Appendix 2. Among interaction terms created, only knew child care by frequency of ANC had significant effect with PNC services utilization. Hence, interaction term, knew child care by frequency of ANC, was included in the final model. Consequently, factors associated with PNC utilization were maternal occupation, frequency of ANC, place of delivery, aware of at least one postpartum danger sign and knew child care by frequency of ANC. The government employed were 3 times $(\mathrm{AOR}=3.01,95 \% \mathrm{CI}(1.36,6.67)$ more likely to utilize PNC as compared to traders. Mothers who had three ANC visits were 4 times $(\mathrm{AOR}=4.29,95 \% \mathrm{CI}=1.59,11.55)$ and who had four ANC visits were 9 times (AOR $=9.55,95 \% \mathrm{CI}$ $=(3.46,26.36)$ more likely to utilize PNC as compared to mothers who had single ANC visit. Mothers from a household where husband alone is a responsible to make decision to use PNC were 3 times more likely to use PNC as compared to a mothers from a household where mother makes decision autonomously. However, decision made by husband alone was not significantly associated with PNC utilization $(\mathrm{AOR}=3.32,95 \% \mathrm{CI}=0.4,27.33)$. Mothers who gave last birth at Health centre were 10.76 times (AOR = $10.76,95 \% \mathrm{CI}=3.26,35.57)$ and at Hospital were 13 times $(\mathrm{AOR}=13.15,95 \% \mathrm{CI}=(3.64,47.50)$ more likely to utilize PNC as compared to mothers who gave their last birth at home. Odds of PNC utilization among reproductive age women who didn't aware for at least one danger signs of postpartum were .06 times $(\mathrm{AOR}=0.06,95 \% \mathrm{CI}=(0.01$, 0.37 ) less likely to utilize PNC as compared to women who aware at least one postpartum danger signs. Mothers who didn't know child care and had three ANC visits were 0.14 times (AOR $=0.13,95 \% \mathrm{CI}=0.02,0.8$ ) less likely to utilize PNC services as compared to mothers knew child care and had one ANC visit (Table 3).

\section{Discussion}

This study aimed to assess PNC utilization and associated factors among reproductive age women. In this study, PNC utilization among reproductive age women was $47.9 \%$. The finding was higher than the national PNC utilization 13\% [6] and other locally conducted studies in Ethiopia; $11 \%$ of Abi-Adi Town in Tigray, 20.2\% of Jabetine district in Amhara region [8], $34.8 \%$ of Dembecha district [7], and 33.5\% of Debre Markos town [9]. Also, the finding is higher than studies conducted abroad of Ethiopia such as $25.1 \%$ of the western district of Nepal [19], 43.2\% of analysis of Nepal Demographic and Health Survey 2011 [14], and 30\% Pakistan [20]. But the finding is lower than $66.8 \%$ of a study conducted at Gondar Zuria district Ethiopia [10], 78.3\% of Adwa town, North Ethiopia [11], and 58\% of Uganda [16]. The difference is might be due to the difference in study setting and method used. This indicates regional variation in the utilization of PNC services and the need for area/ context specific intervention to achieve the HSTP target of postnatal care coverage by 2020 .

Interestingly in this study government employed were more likely to utilize PNC services as compared to traders. A similar result was revealed at a study conducted in Nepal [14]. In contrast, different studies conducted in Ethiopia didn't reveal an association between occupation and PNC utilization [7-11]. The higher tendency of PNC utilization by employed mothers might be due to mothers who are involved in paid employment are more likely to be economically independent and consequently have access to services, and utilize the services when they need or as recommended by their health workers [25]. Evidence showed that having a paid job empowers mothers to utilize maternal health services [26, 29, 30].

Reproductive age women who gave their last birth at a health facility were more likely to utilize PNC services as compared to reproductive age women who 
Table 1 Postnatal care utilization by socio-demographic characteristics of reproductive age women at Halaba Kulito town, Southern, Ethiopia, 2016

\begin{tabular}{|c|c|c|c|c|c|c|}
\hline \multirow[t]{2}{*}{ Characters } & \multicolumn{2}{|c|}{ PNC utilized $(N=191)$} & \multirow{2}{*}{$\begin{array}{l}\text { Total } \\
\text { No (\%) }\end{array}$} & \multirow[t]{2}{*}{ COR } & \multirow[t]{2}{*}{$95 \%$} & \multirow[t]{2}{*}{$\mathrm{Cl}$} \\
\hline & Yes & No & & & & \\
\hline \multicolumn{7}{|l|}{ Age at pregnancy in years } \\
\hline$\leq 18$ years & 26 & 34 & $60(15.0)$ & 0.76 & 0.41 & 1.44 \\
\hline $19-29$ & 110 & 121 & $231(57.6)$ & 0.91 & 0.58 & 1.43 \\
\hline $30-49$ & 55 & 55 & $110(27.4)$ & 1 & & \\
\hline \multicolumn{7}{|l|}{ Current age in years } \\
\hline$\leq 18$ & 11 & 6 & $17(4.2)$ & 0.50 & 0.17 & 1.42 \\
\hline $19-29$ & 133 & 113 & $246(61.3)$ & 0.77 & 0.51 & 1.18 \\
\hline $30-49$ & 66 & 72 & $138(34.4)$ & 1 & & \\
\hline \multicolumn{7}{|l|}{ Marital statues } \\
\hline Single & 3 & 9 & $12(3.0)$ & 0.33 & 0.08 & 1.46 \\
\hline Married & 172 & 185 & $357(89.0)$ & 0.93 & 0.45 & 1.91 \\
\hline Divorced & 16 & 16 & $32(8)$ & 1 & & \\
\hline \multicolumn{7}{|l|}{ Religion } \\
\hline Orthodox & 61 & 59 & $120(29.9)$ & 0.84 & 0.45 & 1.57 \\
\hline Muslim & 97 & 124 & $221(55.1)$ & 0.64 & 0.36 & 1.13 \\
\hline Protestant & 33 & 27 & $60(15)$ & 1 & & \\
\hline \multicolumn{7}{|l|}{ Place of residence } \\
\hline Urban & 197 & 182 & $379(95)$ & 1.33 & 0.56 & 3.19 \\
\hline Rural & 13 & 9 & $22(5.0)$ & 1 & & \\
\hline \multicolumn{7}{|l|}{ Maternal education } \\
\hline Unable to read and write & 31 & 32 & $55(15.7)$ & 0.42 & 0.20 & 0.89 \\
\hline Primary education & 53 & 76 & $129(32.2)$ & 0.31 & 0.16 & 0.59 \\
\hline Junior to high school & 66 & 84 & $150(37.4)$ & 0.34 & 0.18 & 0.65 \\
\hline College and above & 41 & 18 & $59(14.7)$ & 1 & & \\
\hline \multicolumn{7}{|l|}{ Maternal occupation } \\
\hline Trader & 55 & 90 & $145(36.2)$ & 0.93 & 0.43 & 1.97 \\
\hline Private employed & 13 & 23 & $36(9.0)$ & 2.00 & 3.66 & 6.77 \\
\hline Government employed & 47 & 21 & $68(17.0)$ & 1.64 & 1.03 & 2.59 \\
\hline Housewife & 76 & 76 & $152(37.9)$ & 1 & & \\
\hline \multicolumn{7}{|l|}{ Paternal education } \\
\hline Unable to read and write & 10 & 8 & $18(4.5)$ & 0.69 & 0.25 & 1.89 \\
\hline Primary education & 39 & 51 & $90(22.4)$ & 0.42 & 0.24 & 0.74 \\
\hline Junior to high school & 61 & 106 & $167(41.6)$ & 0.32 & 0.19 & 0.52 \\
\hline College and above & 81 & 45 & $126(31.4)$ & 1 & & \\
\hline \multicolumn{7}{|l|}{ Paternal occupation } \\
\hline Unemployed & 1 & 6 & $7(1.7)$ & 0.11 & 0.01 & 0.95 \\
\hline Trader & 82 & 119 & $201(50.1)$ & 0.46 & 0.29 & 0.72 \\
\hline Private employed & 27 & 31 & $58(14.5)$ & 0.58 & 0.31 & 1.08 \\
\hline Government employed & 81 & 54 & $135(33.7)$ & 1 & & \\
\hline \multicolumn{7}{|l|}{ Household monthly income } \\
\hline Below 500ETB & 13 & 38 & $51(12.7)$ & 0.22 & 0.11 & 0.47 \\
\hline 500-1500ЕTB & 48 & 74 & $122(30.4)$ & 0.42 & 0.24 & 0.73 \\
\hline 1500-2500ЕТВ & 70 & 59 & $129(32.2)$ & 0.77 & 0.45 & 1.31 \\
\hline Above 2501ETB & 60 & 39 & $99(24.7)$ & 1 & & \\
\hline
\end{tabular}

* Represents significant association 
gave their last birth at home. The finding is similar to study conducted in Dembacha district Ethiopia [7], Debre Markos town Ethiopia [9], Jabetine district in Amhara region Ethiopia [8], Gondar Zuria district Ethiopia [10], EDHS 2011 [6], western district of Nepal [19], analysis of Nepal Demographic and Health Survey 2011 [14], Royal king of Cambodia
[22], and Bangladesh [23], which revealed that giving birth at health facilities has direct significant association with postnatal care utilization. This might be due to the fact that women who gave birth at health institution have greater opportunity to be informed and educated about types, benefits, and availabilities of PNC services and danger signs of postpartum. This

Table 2 Postnatal care utilization by Obstetric characteristics in Halaba Kulito town, Southern, Ethiopia, 2016

\begin{tabular}{|c|c|c|c|c|c|c|}
\hline \multirow[t]{2}{*}{ Factors } & \multicolumn{3}{|c|}{ PNC utilized ( $N=191)$} & \multirow[t]{2}{*}{ COR } & \multirow[t]{2}{*}{$95 \%$} & \multirow[t]{2}{*}{$\mathrm{Cl}$} \\
\hline & Yes & No & Total N (\%) & & & \\
\hline \multicolumn{7}{|l|}{ Number of pregnancy } \\
\hline Only one & 36 & 53 & $89(22.2)$ & 1 & & \\
\hline Two times & 72 & 75 & $147(36.7)$ & 1.41 & 0.83 & 2.40 \\
\hline Three and more & 82 & 83 & $165(41.1)$ & 1.49 & 0.88 & 2.51 \\
\hline \multicolumn{7}{|l|}{ Number of live birth } \\
\hline One & 38 & 56 & $94(23.4)$ & 1 & & \\
\hline Two & 78 & 77 & $155(38.7)$ & 1.49 & 0.88 & 2.50 \\
\hline Three and more & 75 & 77 & $152(37.9)$ & 1.43 & 0.85 & 2.41 \\
\hline \multicolumn{7}{|c|}{ Total number of children alive } \\
\hline One & 42 & 63 & $105(26.2)$ & 1 & & \\
\hline Two & 77 & 78 & $155(38.7)$ & 1.48 & 0.89 & 2.44 \\
\hline Three and more & 72 & 69 & $141(35.2)$ & 1.56 & 0.94 & 2.61 \\
\hline \multicolumn{7}{|l|}{ Had ANC } \\
\hline Yes & 185 & 177 & $362(90.3)$ & 1 & & \\
\hline No & 6 & 33 & $39(9.7)$ & .174 & 0.07 & 0.42 \\
\hline \multicolumn{7}{|l|}{ Frequency of ANC } \\
\hline One time & 14 & 34 & $48(13.3)$ & 1 & & \\
\hline Two times & 34 & 53 & $87(24.0)$ & 1.56 & 0.73 & 3.32 \\
\hline Three times & 57 & 59 & $116(32.0)$ & 2.34 & 1.14 & 4.83 \\
\hline Four times and above & 80 & 32 & $111(30.7)$ & 6.27 & 2.97 & 13.2 \\
\hline \multicolumn{7}{|l|}{ Place of delivery } \\
\hline Home & 7 & 32 & $39(9.5)$ & 1 & & \\
\hline Health center & 130 & 147 & $277(69.1)$ & 4.0 & 1.72 & 9.47 \\
\hline Hospital & 54 & 31 & $85(21.2)$ & 7.9 & 3.14 & 20.17 \\
\hline \multicolumn{7}{|c|}{ Aware of at least one danger signs of postpartum } \\
\hline Yes & 188 & 183 & $371(92.5)$ & 1 & & \\
\hline No & 3 & 27 & $30(7.5)$ & 0.16 & 0.02 & 1.32 \\
\hline \multicolumn{7}{|l|}{ Source of information } \\
\hline Health professionals & 155 & 113 & $268(72.2)$ & 1 & & \\
\hline Friends, relatives & 10 & 32 & $42(11.3)$ & 0.23 & 0.11 & 0.48 \\
\hline HEWs & 15 & 22 & $37(10.0)$ & 0.49 & 0.25 & 1.00 \\
\hline Radio, television & 8 & 16 & $24(6.5)$ & 0.36 & 0.15 & $0.88)$ \\
\hline \multicolumn{7}{|l|}{ Knew child care } \\
\hline Yes & 154 & 127 & $281(70.1)$ & 1 & & \\
\hline No & 37 & 83 & $120(29.9)$ & 0.37 & 0.23 & $0.57)$ \\
\hline \multicolumn{7}{|l|}{ Who making decision } \\
\hline Wife & 13 & 9 & $22(5.4)$ & 1 & & \\
\hline Husband & 8 & 6 & $14(3.4)$ & 1.65 & 0.69 & 3.97 \\
\hline Both & 170 & 195 & $365(91.0)$ & 1.53 & 0.52 & 4.49 \\
\hline
\end{tabular}

* Represents significant association 
Table 3 Multivariable logistic regression model identifying factors associated with postnatal care utilization among reproductive age women at Halaba Kulito town, Southern, Ethiopia, 2016

\begin{tabular}{|c|c|c|c|}
\hline Factors & AOR & $95 \%$ & $\mathrm{Cl}$ \\
\hline \multicolumn{4}{|l|}{ Maternal Occupation } \\
\hline Trader & 1 & & \\
\hline Private employed & 1.02 & 0.42 & 2.43 \\
\hline Government employed & 3.01 & 1.36 & 6.67 \\
\hline Housewife & 1.62 & 0.90 & 2.90 \\
\hline \multicolumn{4}{|l|}{ Frequency of ANC } \\
\hline One time & 1 & & \\
\hline Two times & 2.03 & 0.74 & 5.55 \\
\hline Three times & 4.29 & 1.59 & 11.55 \\
\hline Four times and above & 9.55 & 3.46 & 26.36 \\
\hline \multicolumn{4}{|l|}{ Place of delivery } \\
\hline Home & 1 & & \\
\hline Health center & 10.76 & 3.26 & 35.57 \\
\hline Hospital & 13.15 & 3.64 & 47.50 \\
\hline \multicolumn{4}{|l|}{ Who make decision } \\
\hline Wife & 1 & & \\
\hline Husband & 3.32 & 0.40 & 27.33 \\
\hline Both & 0.52 & 0.16 & 1.67 \\
\hline Aware at least one postpartum danger sign & & & 0.37 \\
\hline Yes & 1 & & \\
\hline No & 0.06 & 0.01 & 0.37 \\
\hline \multicolumn{4}{|l|}{ Paternal occupation } \\
\hline Unemployed & 1 & & \\
\hline Trader & 0.99 & 0.24 & 4.08 \\
\hline Private employed & 0.57 & 0.15 & 2.22 \\
\hline Government employed & 1.24 & 0.31 & 4.97 \\
\hline \multicolumn{4}{|l|}{ Knew child care } \\
\hline Yes & 1 & & \\
\hline No & 1.62 & 0.40 & 6.60 \\
\hline \multicolumn{4}{|l|}{ Knew child care * Frequency of ANC } \\
\hline Yes by One time & 1 & & \\
\hline No by Two times & 0.54 & 0.09 & 3.30 \\
\hline No by Three times & 0.14 & 0.02 & 0.80 \\
\hline No by Four times and above & 0.13 & 0.02 & 0.79 \\
\hline
\end{tabular}

Hosmer and Lemeshow Test ( $p$-value $=0.523$ )

* Represents significant association

contact improves PNC services seeking behavior of mothers.

In this study, reproductive age women who had three times and four and more times ANC visits during their last pregnancy were more likely to utilize $\mathrm{PNC}$ as compared to mothers had single ANC visit. The finding is similar to study conducted in Dembacha district Ethiopia [7], Gahanna [15], Uganda [16], western district of Nepal [19] and analysis of Nepal Demographic and Health Survey 2011 [14] which revealed that mothers who attended four or more ANC visits were more likely to utilize PNC services.
Evidence showed that ANC attendance and adequate counseling of mothers is associated with increased postnatal care attendance [24]. However, our interaction terms result showed, when mother didn't know child care, high frequency to ANC visits (three times or four or more times) had less significant effect with PNC services utilization. This finding suggests that importance of improving knowledge about child care during antenatal care visits (counselling and health education).

Awareness about postpartum danger signs was directly associated with PNC utilization. Similarly, studies conducted in Jabetine district in Amhara region [8], in Debre Markos town [9], in Hossana [27] and in Nepal [17] revealed that women who were aware at least one obstetric danger sign of pregnancy are more likely to utilize PNC as compared to the women who didn't.

Finally, unlike other studies in Ethiopia [8, 9, 28] which revealed that educational status of the women, and husbands were determinants of PNC utilization, these factors didn't determine PNC service utilization in the current study.

\section{Strength and limitation}

The conclusion of this study was derived from primary data through rigours descriptive and analytic data analysis. However, the study had some limitations. Hence, interpretation of the results needs certain consideration. Because the study use cross-sectional data, the study unable to conclude definite temporal relationship between independent and dependent variables. So that, associations were looked for. Also, in this study data were collected retrospectively, this might introduce recall bias. To reduce recall bias women who gave a live birth in 2015 only were recruited for the study. Small sample size is another limitation of this study. Single population proportion formula was used to derive optimum sample size for PNC service utilization and double population proportion formula was used to derive optimum sample size to determine associated factors. However, sample size calculated using single population formula was judged sufficient source to identify associated factors with PNC services utilization.

\section{Conclusion}

This study assessed PNC utilization and associated factors among reproductive age women. The study results provided a basic understanding of factors that associated with PNC utilization by reproductive age women. The findings of this study showed direct association between postnatal care utilization and maternal employment, awareness to postpartum danger signs, frequency of ANC and attending birth at health institution. Therefore, the results suggested contextspecific evidence which might be taken into consideration when rethinking policies to increase PNC utilization. 


\section{Appendix}

Appendix 1

Table 4 Table indicates multicollinearity (Variance Inflation Factors)

\begin{tabular}{|c|c|c|c|c|c|c|c|c|c|c|}
\hline \multicolumn{11}{|c|}{ Coefficients $^{a}$} \\
\hline \multirow{2}{*}{\multicolumn{2}{|c|}{ Model }} & \multicolumn{2}{|c|}{$\begin{array}{l}\text { Unstandardized } \\
\text { Coefficients }\end{array}$} & \multirow{2}{*}{$\begin{array}{l}\text { Standardized } \\
\text { Coefficients } \\
\text { Beta }\end{array}$} & \multirow[t]{2}{*}{$\mathrm{t}$} & \multirow[t]{2}{*}{ Sig. } & \multicolumn{2}{|c|}{$\begin{array}{l}\text { 95.0\% Confidence } \\
\text { Interval for B }\end{array}$} & \multicolumn{2}{|c|}{$\begin{array}{l}\text { Collinearity } \\
\text { Statistics }\end{array}$} \\
\hline & & $B$ & $\overline{\text { Std. Error }}$ & & & & Lower Bound & Upper Bound & Tolerance & VIF \\
\hline & (Constant) & .434 & .285 & & 1.526 & .128 & -.125 & .994 & & \\
\hline & Religion & -.013 & .037 & -.017 & -.345 & .730 & -.085 & .059 & .946 & 1.057 \\
\hline & Maternal Occupation & .035 & .019 & .090 & 1.819 & .070 & -.003 & .072 & .936 & 1.068 \\
\hline & Husband educational status & .019 & .028 & .047 & .672 & .502 & -.036 & .074 & .467 & 2.143 \\
\hline & Husband occupation & .024 & .035 & .045 & .695 & .488 & -.044 & .092 & .538 & 1.858 \\
\hline & Monthly income & .032 & .031 & .062 & 1.020 & .309 & -.030 & .093 & .615 & 1.626 \\
\hline \multirow[t]{11}{*}{1} & Number of pregnancy & .076 & .103 & .117 & .737 & .462 & -.127 & .279 & .091 & 10.991 \\
\hline & Number of live birth & -.212 & .138 & -.324 & -1.533 & .126 & -.483 & .060 & .051 & 19.482 \\
\hline & No of children currently & .179 & .102 & .276 & 1.756 & .080 & -.022 & .379 & .093 & 10.802 \\
\hline & How many ANC visit & .112 & .028 & .228 & 4.037 & .000 & .057 & .167 & .717 & 1.395 \\
\hline & Place of delivery & .178 & .051 & .187 & 3.498 & .001 & .078 & .279 & .804 & 1.244 \\
\hline & Who making decision & -.124 & .054 & -.113 & -2.300 & .022 & -.229 & -.018 & .952 & 1.050 \\
\hline & Knew child care & -.157 & .060 & -.131 & -2.618 & .009 & -.275 & -.039 & .915 & 1.093 \\
\hline & Aware at least one postprt danger sign & -.396 & .141 & -.136 & -2.801 & .005 & -.674 & -.118 & .974 & 1.027 \\
\hline & Mother's current age & .092 & .076 & .097 & 1.204 & .229 & -.058 & .242 & .356 & 2.805 \\
\hline & Age at pregnancy & -.119 & .065 & -.149 & -1.830 & .068 & -.247 & .009 & .346 & 2.889 \\
\hline & Maternal education & -.011 & .033 & -.020 & -.337 & .737 & -.075 & .053 & .645 & 1.550 \\
\hline
\end{tabular}

a.Dependent Variable: postnatal care utilization 


\section{Appendix 2}

Table 5 Model with interaction term

\begin{tabular}{|c|c|c|c|c|c|c|c|c|}
\hline \multirow[t]{2}{*}{ Variables in the Equation } & \multirow[t]{2}{*}{$B$} & \multirow[t]{2}{*}{ S.E. } & \multirow[t]{2}{*}{ Wald } & \multirow[t]{2}{*}{$d f$} & \multirow[t]{2}{*}{ Sig. } & \multirow[t]{2}{*}{$\operatorname{Exp}(B)$} & \multicolumn{2}{|c|}{ 95\% C.I.for EXP(B) } \\
\hline & & & & & & & Lower & Upper \\
\hline \multicolumn{9}{|l|}{ Maternal Occupation } \\
\hline Trader & & & 8.517 & 3 & .036 & & & \\
\hline Private employed & .015 & .446 & .001 & 1 & .974 & 1.015 & .424 & 2.430 \\
\hline Government employed & 1.103 & .405 & 7.418 & 1 & .006 & 3.014 & 1.363 & 6.669 \\
\hline Housewife & .479 & .299 & 2.569 & 1 & .109 & 1.615 & .899 & 2.902 \\
\hline \multicolumn{9}{|l|}{ Frequency of ANC } \\
\hline One time & & & 25.919 & 3 & .000 & & & \\
\hline Two times & .706 & .514 & 1.884 & 1 & .170 & 2.026 & .739 & 5.553 \\
\hline Three times & 1.456 & .505 & 8.310 & 1 & .004 & 4.290 & 1.594 & 11.547 \\
\hline Four times and above & 2.257 & .518 & 19.002 & 1 & .000 & 9.554 & 3.463 & 26.356 \\
\hline \multicolumn{9}{|l|}{ Place of delivery } \\
\hline Home & & & 16.363 & 2 & .000 & & & \\
\hline Health center & 2.376 & 610 & 15.175 & 1 & .000 & 10.761 & 3.256 & 35.567 \\
\hline Hospital & 2.576 & .655 & 15.451 & 1 & .000 & 13.147 & 3.639 & 47.503 \\
\hline \multicolumn{9}{|l|}{ Who make decision } \\
\hline Wife & & & 5.592 & 2 & .061 & & & \\
\hline Husband & 1.200 & 1.076 & 1.245 & 1 & .265 & 3.320 & .403 & 27.332 \\
\hline Both & -.659 & .599 & 1.210 & 1 & .271 & .518 & .160 & 1.673 \\
\hline \multicolumn{9}{|c|}{ Aware at least one postpartum danger sign } \\
\hline \multicolumn{9}{|l|}{ Yes } \\
\hline nO & -2.768 & .909 & 9.271 & 1 & .002 & .063 & .011 & .373 \\
\hline \multicolumn{9}{|l|}{ Paternal occupation } \\
\hline Unemployed & & & 7.268 & 3 & .064 & & & \\
\hline Trader & -.007 & .720 & .000 & 1 & .993 & .993 & .242 & 4.075 \\
\hline Private employed & -.558 & .692 & 649 & 1 & .420 & .572 & .147 & 2.224 \\
\hline Government employed & .215 & .709 & .092 & 1 & .762 & 1.239 & .309 & 4.973 \\
\hline \multicolumn{9}{|l|}{ Knew child care } \\
\hline \multicolumn{9}{|l|}{ Yes } \\
\hline No & .484 & .716 & .457 & 1 & .499 & 1.623 & .399 & 6.601 \\
\hline \multicolumn{9}{|c|}{ Knew child care ${ }^{*}$ Frequency of ANC } \\
\hline Yes by One time & & & 7.800 & 3 & .050 & & & \\
\hline No by Two times & -.618 & .924 & .447 & 1 & .504 & .539 & .088 & 3.297 \\
\hline No by Three times & -1.970 & .888 & 4.923 & 1 & .026 & .139 & .024 & .795 \\
\hline No by Four times and above & -2.056 & .931 & 4.882 & 1 & .027 & .128 & .021 & .793 \\
\hline Constant & -2.900 & 1.213 & 5.717 & 1 & .017 & .055 & & \\
\hline
\end{tabular}




\section{Acknowledgements}

Our warm gratitude goes to data collectors for their diligence and dedication in collecting and inputting a high-quality data used for the study. Also, the authors appreciate the study participants for their cooperation and providing necessary information. We acknowledge the local administrators and the community for their strong support during the study period.

\section{Funding}

Not applicable.

\section{Availability of data and materials}

Data on which conclusion was made were presented using a table.

\section{Authors' contributions}

TA and DJ have made substantial contributions to conception and design or analysis and interpretation of data; have been involved in drafting the manuscript or revising it critically for important intellectual content; have given final approval of the version to be published; and agree to be accountable for all aspects of the work in ensuring that questions related to the accuracy or integrity of any part of the work are appropriately investigated and resolved.

\section{Ethics approval and consent to participate}

Support letter was obtained from Hawassa University College of Medicine and Health Sciences Ethical Review Board. Permission to proceed the study was attained from town health office administrative officials. Verbal consent was obtained from the study participants after the brief explanation given on the objectives as well as the benefit of the study. Confidentiality and privacy of every respondent's information were ensured by not using any identifiers of the study participants.

\section{Consent for publication}

This is our original research work. We want to publish it at archives of public health

\section{Competing interests}

The authors declare that they have no competing interests.

\section{Publisher's Note}

Springer Nature remains neutral with regard to jurisdictional claims in published maps and institutional affiliations.

Received: 30 April 2017 Accepted: 19 November 2017 Published online: 08 February 2018

\section{Reference}

1. World Health Organization. WHO technical consultation on postpartum and postnatal care. Geneva: WHO; 2010.

2. World Health Organization. Postpartum Care of the Mother and Newborn: a practical guide. Volth edition. Geneva: WHO; 1998. WHO/RHT/MSM/983

3. Darmstadt GL, Bhutta ZA, Cousens S, Adam T, Walker N, et al. Evidencebased, cost-effective interventons: how many newborn babies can we save? Lancet. 2005;365:977-88.

4. World Health Organization. WHO recommendations on postnatal care of mother and newborn. Geneva: World Health Organization; 2013.

5. World Health Organization. World health statistics 2013. Geneva: World Health Organization; 2013.

6. Central Statistical Agency [Ethiopia] and ICF International. Ethiopia demographic and health survey 2011. Addis Ababa, Ethiopia and Calverton, Maryland, USA: Central Statistical Agency and ICF International; 2012.

7. Hordofa MA, Almaw SS, Berhanu MG, Lemiso HB. Postnatal care service utilization and associated factors among women in Dembecha District, Northwest Ethiopia. Science Journal of Public Health. 2015;3(5):686-92. https://doi.org/10.11648/.j.jph.20150305.24.

8. Workineh YG, Hailu DA. Factors affecting utilization of postnatal Care Service in Amhara Region, Jabitena District, Ethiopia. Science Journal of Public Health. 2014:2(3):169-76. https://doi.org/10.11648/.jsph.20140203.15.

9. Limenih M, Endale Z, Dachew B. Postnatal care service utilization and associated factors among women who gave birth in the last 12 months prior to the study in Debre Markos town, Northwestern Ethiopia: a community-based cross-sectional study. Int J Reprod Med. 2016. Article ID 7095352:7.

10. Tesfahun F, Work W, Mazengiya F, Kifle M. Knowledge, perception, and utilization of postnatal care of mothers in Gondar Zuria District, Ethiopia: a cross-sectional study. Maternal and ChildHealth Journal. 2014;18(10):2341-51.

11. Berhe H, Tilahun W, Aregay A, Bruh G, Gebremedhim H. Utilisation and associated factors of postnatal care in Adwa town, Tigray, Ethiopia-a crosssectional study. Advanced Research in Pharmaceuticals and Biologicals. 2013:3(1):353-9.

12. The Federal Democratic Republic of Ethiopia Ministry of Health. Health sector transformation plan 2015/16-2019/20. 2015.

13. Worku $\mathrm{G}$, et al. Factors affecting utilization of skilled maternal care in Northwest Ethiopia: a multilevel analysis. BMC Int Health Hum Rights. 2013; 13:20

14. Khanal $\mathrm{V}$, et al. Factors associated with the utilization of postnatal care services among the mothers of Nepal: analysis of Nepal demographic and health survey 2011. BMC Womens Health. 2014;14:19.

15. Doku D, et al. Factors associated with reproductive health care utilization among Ghanaian women. BMC Int Health Hum Rights. 2012;12:29.

16. Kabuya Aminah. Factors determining the utilization of postpartum care services in Uganda, UDHS, 2006.

17. Dhakal $\mathrm{S}$, et al. Utilization of postnatal care among rural women in Nepal. BMC pregnancy and child birth. 2007;7(19)

18. Dhakal S, Chapman GN, Simkhada PP, Van Teijlingen ER, Stephens J, Raja AE. Utilisation of postnatal care among rural women in Nepal. BMC Pregnancy Childbirth. 2007:7:19. https://doi.org/10.1186/1471-2393-7-19.

19. Paudel M, Khanal V, Acharya B, Adhikari M. Determinants of postnatal service utilization in a Western District of Nepal: community based cross sectional study. J Women's Health Care. 2013;2:126. https://doi.org/10.4172/ 2167-0420.1000126.

20. Sultana N, Shaikh BT. Low utilization of postnatal care: searching the window of opportunity to save mothers and newborns lives in Islamabad capital territory, Pakistan. BMC Res Notes. 2015;8:645.

21. Nankwanga A. Factors influencing utilization of postnatal services in Mulago and Mengo hospitals [master thesis], Kampala. Uganda: University of the Western Cape; 2004

22. Ith P, Dawson A, Homer CSE, Whelan AK. Practices of skilled birth attendants during labor, birth and the immediate postpartum period in Cambodia. Midwifery. 2013;29(4):300-7.

23. Mosiur Rahman M, Haque SE, Sarwar Zahan M. Factors affecting the utilization of postpartum care among young mothers in Bangladesh. Health and Social Care in the Community. 2011;19(2):138-47.

24. Rahman $\mathrm{M}$, Haque $\mathrm{S}$, Zahan $\mathrm{M}$. Factors affecting the utilization of postpartum care among young mothers in Bangladesh. Health Soc Care Comm. 2011;19(2):138-47.

25. Chakraborty N, Islam M, Chowdhury Rl, Bari W. Utilisation of postnatal care in Bangladesh: evidence from a longitudinal study. Health Soc Care Comm. 2002:10(6):492-502.

26. Salam A, Siddiqui S. Socioeconomic inequalities in use of delivery care services in India. J Obstet Gynecol India. 2006:56(2):123-7.

27. Dutamo $Z$, et al. Maternal health care use among married women in Hossaina, Ethiopia. BMC Health Serv Res. 2015;15:365.

28. Tarekegn SM, et al. Determinants of maternal health service utilization in Ethiopia: analysis of the 2011 Ethiopian demographic and health survey BMC Pregnancy and Childbirth. 2014:14:161.

29. Rwabufigiri BN, et al. Factors associated with postnatal care utilization in Rwanda: a secondary analysis of 2010 demographic and health survey data. BMC Pregnancy and Childbirth. 2016;16:122. https://doi.org/10.1186/s12884016-0913-0.

30. Jayaraman A, Chandrasekhar S, Gebreselassie T. Factors affecting maternal health care seeking behavior in Rwanda. DHS working paper no. 59. 2008.

31. Neter J, Kutner M, Wasserman W, Nachtsheim C, Neter J. Applied linear regression models 4th ed. Irwin: McGraw-Hill; 2004. 